\title{
Maternal Perception about Neonatal Jaundice in Eastern Nepal: A Qualitative Study
}

\section{Dinesh Dharel ${ }^{1 *}$, Asmita Bhattarai ${ }^{2}$}

${ }^{1}$ BP Koirala Institute of Health Sciences (BPKIHS), Dharan, Sunsari, Nepal ${ }^{2}$ Pneumococcal Impact Economic Study (PIES) Project, Nepal Pediatric Society, Nepal and International Vaccine Access Centre, John Hopkins University, USA

\begin{abstract}
Background: Jaundice is a common problem in newborn babies and mothers have different misconceptions about it in Nepal. This study was conducted to explore mother's perception about the causes, recognition, management and outcome of neonatal jaundice.
\end{abstract}

Methodology: In-depth interviews were conducted with 32 mothers of infants under six months of age with a history of jaundice in the neonatal period attending the outpatient department of Ilam District Hospital.

Received:

23 March 2016 Audio-taped data were transcribed and analyzed thematically.

Revised:

June 132016

Accepted:

20 September 2016

\section{${ }^{\star}$ Correspondence:}

dineshdharel13@gmail.com BP Koirala Institute of Health Sciences, Dharan
Results: Most of the mothers recognized jaundice in babies from yellow skin but some noticed it after being alerted by health workers or other people. They perceived jaundice in neonates as a serious condition. However, they were unclear about the cause and attributed it to breach in food restrictions, lack of hygiene or effect of evil spirits. Foods consumed by mothers during and after pregnancy were of concern, not only as a cause but also a remedial measure of jaundice. They usually resorted to traditional measures of avoiding certain foods and reported that health workers did not offer specific remedies and that some health workers even approved such practices. The perceptions of mothers were greatly influenced by family and societal beliefs and practices such as applying oil, sunbathing or avoiding various foods by mothers, often irrespective of advice from health workers. Mother-in-law and the health worker have had the prominent influence in mother's perception.

Conclusion: The perceptions of mothers regarding recognition, seriousness, causes and treatment of jaundice in their newborn babies were mostly guided by their own misconceptions and experiences. However, the family and societal beliefs apparently had a big influence.

Keywords: Neonatal jaundice, qualitative, perspectives, themes, Nepal, developing country, food taboo, tradition

Suggested citation: Dharel D, Bhattarai A. Maternal Perception about Neonatal Jaundice in Eastern Nepal: A Qualitative Study. Health Prospect. 2016; 15(3):

Tweetable abstract: Perception of mothers about jaundice in newborn babies reflects their misconception and experience and also their family or societal belief

\section{Introduction}

Jaundice is a yellowish discoloration of the skin and/or whites of the eyes that is seen in up to $60 \%$ of term and $80 \%$ of preterm neonates globally (1). In Nepal, out of 18,985 newborn infants born in Sarlahi District from May 2003 through January 2006, the incidence of referral for neonatal jaundice was 29.3 per 1000 live births (2). Infants with high blood levels of bilirubin, called hyperbilirubinemia, develop the yellow color when bilirubin accumulates in the skin. Severe hyperbilirubinemia can be toxic to the nervous system of infants, potentially causing acute reversible brain damage called bilirubin encephalopathy or permanent brain damage called kernicterus.

"Physiologic jaundice" is a benign form of jaundice which develops between 72 and 96 hours after birth in majority of newborn babies and usually goes away by one to two weeks after birth. However, estimated 1.1 million babies develop severe hyperbilirubinemia worldwide every year, majority of which occur in Sub-Saharan Africa and South Asia (3). Jaundice is common in infants who are breastfed either due to inadequate intake of breast milk or due to infant's immature liver and intestines to handle breast milk protein. Other important reason for hyperbilirubinemia in some infants is excess production of bilirubin from conditions that have increased red blood cell breakdown. It can occur in sick babies with infection or in babies with hypothyroidism, neonatal hepatitis or biliary atresia (4).

Infants with mild jaundice usually need no treatment. Infants with bilirubin levels higher than safe level for that baby will require treatment but all infants with jaundice should be monitored by a health worker. Increasing the mother's milk supply, frequent feeding, and ensuring good sucking (latch) are the best treatments for jaundice due to inadequate intake. Breast milk jaundice is not a reason to stop breastfeeding as long as the baby is feeding well, gaining weight, and otherwise thriving (5). Various restrictions on food are imposed upon mother with a belief that certain food increases the jaundice and such myths probably stem from the commonly held food taboos regarding infectious hepatitis in older children or adults. Exposure to sunlight was previously thought to be helpful, but is not currently 
recommended due to the risk of sunburn (5).

Sunburn does not occur with the lights used in phototherapy when used properly. Phototherapy is given for treatment of jaundice beyond safe bilirubin level. It is usually effective and does not cause burn. Infants who are at risk for hyperbilirubinemia need close surveillance and follow up.

There are multitudes of misconceptions among mothers regarding neonatal jaundice. Several quantitative and knowledge, attitude and practice (KAP) studies have been conducted about neonatal jaundice $(6,7)$. However, not many studies have been done on the perception of mothers who went through the experience of their baby having jaundice. As the mother is the primary care giver for babies in most of the societies, the perception of mothers in understanding and dealing with neonatal jaundice would make a significant difference in the disease outcome. This would in turn help health care providers in making appropriate treatment decisions for the baby and more importantly, in counseling mother and her family.

Therefore, this study was conducted to explore mothers' perception about the causes, recognition, management and outcome of neonatal jaundice.

\section{Methods}

This was an exploratory study conducted in Ilam, a hilly district in the easternmost part of Nepal. The study was undertaken in the outpatient department (OPD) of the district hospital which serves as one of the university teaching hospitals for BP Koirala Institute of Health Sciences, Dharan, Nepal.

The study participants were mothers of infants under six months of age with history of jaundice in the neonatal period, presenting with any complaints at outpatient department of Ilam District Hospital during April/May 2015.

The participants were selected purposively. The mothers of all eligible infants presenting to the investigator in the OPD over the study period were invited to participate in the study and those who provided informed written consent to participate and audio tape interview were enrolled in the study. The district hospital provided approval for the study.

Data was collected by DD over the period of April 20th to May 13th, 2015. A total of 32 in-depth interviews were conducted till saturation of information was reached. Guidelines for the in-depth interview were first drafted in English and then translated into Nepali and the interviews were conducted in Nepali language. The interview guidelines were pretested to check for appropriateness and comprehensibility of language used and coherence of information. The investigator conducted two to three interviews in a day, each interview lasting for about thirty minutes. The perceptions of mother about jaundice in their infant during the neonatal period were explored by asking open ended questions, probing as necessary.

Data were analyzed qualitatively. Four domains for data categorization were determined before data analysis: recognition of jaundice, causes, management and outcome of neonatal jaundice. The tape-recorded data were transcribed in Nepali first and then translated to English for the purpose of analysis. The responses were initially categorized under the four predetermined domains. Categories were refined based on the themes emerging and open coding was done. The codes in each domain were analyzed for meaningful relationship among them to derive the perceptions through axial coding. A conceptual framework was constructed by arranging the themes that emerged from open and axial coding (8).

\section{Results}

A total of 32 mothers were interviewed with a mean age of 24.03 years, and a standard deviation of 4.26 years. Two-third of the women were primi mothers and the majority (63\%) delivered at a health facility. More than three-fourth mothers breastfed only in the first month of the birth. Around half of the respondents (44\%) did not have any formal education and less than a third had higher education beyond secondary level (31\%). Two-third mothers were home makers while a quarter of them were involved in service and the remaining in business. Majority of the women ( $82 \%$ ) were Hindu by religion and about half of them (47\%) were Brahmin/Chhetri followed by Janajati (38\%). (Table 1 in annex)

Figure 1 presents a conceptual framework that summarises the themes that emerged through open and axial coding (Table 2 in annex) of the in-depth interview data on mothers' perception towards neonatal jaundice.

\section{Recognition of Neonatal Jaundice:}

Most of the mothers discerned their babies had jaundice from their yellow eyes or skin but some realized only after health workers informed them about the diagnosis. Sometimes, a mother would know about jaundice in her baby when somebody else in the family noticed and told her.

"While rubbing oil under the sunlight, my mother-in-law saw that my baby looked yellowish..."

"When we were packing up to get discharged from hospital after second day of normal delivery, the doctor said that my baby had jaundice."

\section{Causes of Neonatal Jaundice:}

Foods that mothers consumed during and after pregnancy were thought to be the cause of jaundice in newborn baby. Some mothers even felt guilty of breaching food taboos while some did not believe the taboos but were supposed to comply with such restrictions out of respect to elders.

"My mother in law accused me of not taking care about my food. I was barred (after my baby developed jaundice) from taking meat, ghee (a type of clarified butter) and 'besar' (turmeric) for the fear of aggravating jaundice. I don't think that has anything to do with baby's jaundice, but I had no choice when elders told me to avoid them. Jaundice subsided over a week's time."

"I duly complied with the food restrictions during the pregnancy, except for noodles which I ate when I was too nauseated to eat rice. I repent that I ate noodles."

"I ate only jaulo (rice and vegetable pudding) and soup of 'jwano' (Thyme seed) for almost a month for the fear of jaundice returning, even though she (health worker) had advised that I could eat any nutritious food."

Some mothers also attributed jaundice to unseen forces, particularly related to perceived evil spirits. 
"I do not know how my baby got jaundice. He was born fine and all of a sudden he was fussy and I saw that his body was yellow. I never had had jaundice myself, nor anybody in my blood (relatives). You never know who all are following you front and back, you know what I mean!"

Mothers opined lack of hygiene as a cause of jaundice. Jaundice was also thought to occur because of impurity in blood.

"If you do not keep your baby clean, he will catch jaundice."

"I think jaundice occurs when the blood is impure."

\section{Management of Neonatal Jaundice:}

Mothers usually resorted to the traditional measures such as sun bathing the babies and avoiding certain foods. Some women reported that health workers did not offer specific remedies and some even approved their traditional treatment measures. Others admitted that even though they were initially seen and counseled by the health workers, they resorted back to their traditional practices due to their firm belief in traditional oil massage under sunlight as a preventive and curative measure for jaundice.

"As soon as I saw that my baby had yellow eyes, I took her to local health post. The health worker said he had no medicine for jaundice. He asked me to control the food I eat and come back if the baby becomes sicker."

"When my baby had jaundice few days after birth, I applied pure mustard oil more frequently and kept under the sunlight." "The 'health worker' repeatedly told me not to worry, but to keep the baby in morning sunlight. Jaundice increased the next day and we took her to 'faith healer' who did some rituals to take jaundice away and also applied something on her body. I strictly avoided the foods as per his advice. Jaundice gradually subsided over a week."

\section{Outcome of Neonatal Jaundice:}

Mothers perceived jaundice as a serious condition, although they did not clearly state its manifestations. Their perception of outcome was influenced by what they had seen or heard and sometimes that changed with their own experience.

"My baby was very sick three days after birth. When I noted that he was passing a little amount of yellow urine, and was not breastfeeding, I took him to hospital, where he was admitted for ten days. He was kept under special light for many days. I was told that I can take all my regular meal. I was worried that my only baby would die or be disabled, but luckily he looks fine now (at five months of age). We had to spend a lot of money and I had to struggle hard to convince my family. Now I am happy that I could take my baby out from the death bed, even though we had to sell our buffalo. I will tell other people in my village that if baby gets jaundice, take him to hospital and you can save his life."

\section{Influences on Maternal Perception - The New Theme:}

The influence of family and societal beliefs and practices on mothers' perception about neonatal jaundice emerged strongly during the analysis. This theme was not part of the original conceptual framework but it emerged in the domains of recognition, causes, management and outcome of jaundice . The elders in the family, particularly the mother-in-law had a strong influence on the mothers' practices and perceptions on neonatal jaundice. Moreover, other people directly or indirectly linked to the baby's health care and wellbeing, such as the female community health volunteers, health workers and faith healers had important influence on different aspects of mother's perception.

\section{Discussion}

Mothers expressed varied concerns about jaundice in their newborn, which mainly centered on taboos they held in relation to jaundice from infectious hepatitis. Mothers perceived food as a causal factor of jaundice and abided by the food taboos for its management in their newborns. Family members and conventional healers had a great influence on the mothers in such perceptions and practices. Studies conducted in other countries report similar misconceptions.

In a Nigerian study, one-third of the study participants erroneously believed that eating too much groundnut in pregnancy causes jaundice while more than one-fifth believed mosquito bite transmits jaundice. Moreover, half of them believed that exposure to sunlight would cure jaundice and a quarter believed drinking glucose solution will treat jaundice (6).

Some studies have shown better knowledge while some have demonstrated poor knowledge of expectant mothers regarding jaundice in neonatal period. A descriptive cross sectional study done among 389 expectant mothers at University of Benin Teaching Hospital showed that majority of the mothers were aware of neonatal jaundice, could recognize it from symptoms, had some idea about complications and knew correct management of jaundice. This good knowledge was significantly associated with their educational level and previous experience of having previous babies with jaundice (7). Another similar study conducted at Mariere Memorial Central Hospital showed that majority were aware about jaundice but knowledge regarding risk factors/causes and treatment was unsatisfactory (9).

While most of the previous studies focused on knowledge and attitude and few on practice of mothers regarding jaundice in newborn babies through quantitative methods, this study focused on the qualitative aspects of mothers who experienced such first-hand provides a new perspective to this problem.

In a qualitative study using grounded theory methods that interviewed 47 breastfeeding mothers of otherwise healthy infants with a diagnosis of neonatal jaundice and treated in university and community hospitals, mothers showed concerns about jaundice in newborn babies and perceived it as serious. The expressed themes were guilt for causing jaundice in their babies, concern about yellow skin, discomfort about jaundice management, worries about the short- and longterm effects and misconceptions about jaundice which they wished to have explained by the medical staff. The differences in culture, language barriers, quality of information received, unexpectedness of and lack of knowledge about jaundice, duration of illness, level of intervention, interaction with mothers having similar experience and with the health care professionals contributed to the perceptions mothers expressed (10).

In this study, maternal perceptions generally contradicted the modern medical knowledge on neonatal jaundice, though some scientifically sound themes were also evident. In addition, there was obvious influence of family and 
societal values in their perception. These are valuable findings in informing correct ways of counseling the mothers about jaundice in their newborn babies. The findings also demand that the health care providers involve other family members in counseling, and particularly the mother-in-law considering her strong influence on the mohers of the infants with jaundice.

However, the inability to quantify the proportion of respondents who held certain perception and the degree of influence was a limitation owing to the qualitative design of the study. Since mothers were interviewed during their hospital visit, the findings may not represent the general community. Conducting a mixed method study involving larger number of mothers from communities could provide a clearer picture of maternal perception and behaviour regarding neonatal jaundice, so as to guide interventions to improve their knowledge and practice.

\section{Conclusion}

The perception of mothers regarding recognition, seriousness, causes and treatment of jaundice in their newborn babies mostly reflected their own misconceptions about this common neonatal problem. The experience of mothers caring for children with jaundice in their neonatal period along with the influence of their family and society evidently shaped their perceptions about neonatal jaundice.

\section{Acknowledgement}

I express my gratitude all 32 mothers of infants I interviewed for this study as well as the management and staff of District Hospital Ilam for their kind cooperation. I also acknowledge the faculties of my department at BPKIHS, especially Prof Rupa Rajbhandari Singh (Chair, Department of Pediatrics and Adolescent Medicine) for their kind support and guidance in conducting this study.

\section{References}

1. Young Infants Clinical Signs Study Group. Clinical signs that predict severe illness in children under age 2 months: a multicentre study. The Lancet. 2008 Jan 18;371(9607):135-42.

2. Scrafford CG, Mullany LC, Katz J, Khatry SK, LeClerq SC, Darmstadt GL, Tielsch JM. Incidence of and risk factors for neonatal jaundice among newborns in southern Nepal. Tropical Medicine \& International Health. 2013 Nov 1;18(11):1317-28.

3. Bhutani VK, Zipursky A, Blencowe H, Khanna R, Sgro M, Ebbesen F, Bell J, Mori R, Slusher TM, Fahmy N, Paul VK. Neonatal hyperbilirubinemia and Rhesus disease of the newborn: incidence and impairment estimates for 2010 at regional and global levels. Pediatric research. 2013 Dec 1;74(S1):86-100

4. Gourley GR. Neonatal jaundice and disorders of bilirubin metabolism. Liver Disease in Children. 2nd ed. Philadelphia, Pa: Lippincott Williams \& Wilkins. 2001:275-314.

5. Ip S, Chung M, Kulig J, et al. An evidence based review of important issues concerning neonatal hyperbilirubinemia. Pediatrics 2004; 114:e130.

6. Eneh AU1, Ugwu RO, Perception of neonatal jaundice among women attending children out patient and immunization clinics of the UPTH Port Harcourt. Niger J Clin Pract. 2009 Jun;12(2):187-91.

7. Egube BA, Ofili AN, Isara AR, Onakewhor JU. Neonatal jaundice and its management: knowledge, attitude, and practice among expectant mothers attending antenatal clinic at University of Benin Teaching Hospital, Benin City, Nigeria. Niger J Clin Pract. 2013 Apr-Jun;16(2):188-94

8. Corbin J, Strauss A. Basics of qualitative research: Techniques and procedures for developing grounded theory. Sage publications; 2014 Nov 25.9. Okposio M.M, Adebanjo E. O. Evaluation of knowledge and perception of newborn jaundice among parturient mothers in a secondary health care centre in the Niger Delta region of Nigeria. Bangladesh Journal of Medical
Science. 2014; 13(3): p.292-297

9. Hannon PR, Willis SK, Scrimshaw SC. Persistence of maternal concerns surrounding neonatal jaundice: an exploratory study. Archives of pediatrics \& adolescent medicine. 2001 Dec 1;155(12):1357-63.

10. Hannon PR, Willis SK, Scrimshaw SC. Persistence of maternal concerns surrounding neonatal jaundice: an exploratory study. Archives of pediatrics \& adolescent medicine. 2001 Dec 1;155(12):1357-63.

Table 1: Baseline characteristics of the participants

\begin{tabular}{|c|c|c|}
\hline Baseline Characteristics & Statistic & Percentage \\
\hline Age $($ mean $\pm \mathrm{SD})$ & $24.03( \pm 4.26)$ years & \\
\hline \multicolumn{3}{|l|}{ Parity: } \\
\hline Primi & 21 & $66 \%$ \\
\hline Multi & 11 & $33 \%$ \\
\hline \multicolumn{3}{|l|}{ Ethnicity: } \\
\hline Brahmin/Chhetri & 15 & $47 \%$ \\
\hline Janajati & 12 & $38 \%$ \\
\hline Dalit & 5 & $15 \%$ \\
\hline \multicolumn{3}{|l|}{ Religion: } \\
\hline Hindu & 26 & $82 \%$ \\
\hline Buddhist & 4 & $12 \%$ \\
\hline Christian & 2 & $6 \%$ \\
\hline \multicolumn{3}{|l|}{ Educational status: } \\
\hline No formal education & 14 & $44 \%$ \\
\hline Primary & 3 & $09 \%$ \\
\hline Secondary & 5 & $16 \%$ \\
\hline Above secondary & 10 & $31 \%$ \\
\hline \multicolumn{3}{|l|}{ Occupation: } \\
\hline Homemaker & 21 & $66 \%$ \\
\hline Business & 3 & $09 \%$ \\
\hline Service & 8 & $25 \%$ \\
\hline \multicolumn{3}{|l|}{ Place of Delivery: } \\
\hline Institutional & 20 & $63 \%$ \\
\hline Home & 12 & $37 \%$ \\
\hline \multicolumn{3}{|l|}{$\begin{array}{l}\text { Exclusive Breastfeeding in the } \\
\text { first month: }\end{array}$} \\
\hline Yes & 25 & $78 \%$ \\
\hline No & 7 & $22 \%$ \\
\hline
\end{tabular}


Table 2: Open and Axial Codes

\begin{tabular}{|c|c|c|}
\hline Domains & Open codes & Axial code definition \\
\hline Recognition of jaundice & $\begin{array}{l}\text { Yellow eyes/skin } \\
\text { Yellow urine } \\
\text { After being told by health worker } \\
\text { Noticed by other family members or relatives }\end{array}$ & \multirow[t]{5}{*}{$\begin{array}{l}\text { Food taken during and after pregnancy } \\
\text { as cause and remedy } \\
\text { Effect of evil forces, waived by rituals } \\
\text { May not notice jaundice unless told by } \\
\text { others } \\
\text { Resorted to traditional measures as } \\
\text { health workers did not offer specific } \\
\text { remedies } \\
\text { Perceive as serious condition but do not } \\
\text { know the reason } \\
\text { Perception influenced by family and so- } \\
\text { cietal beliefs and practices }\end{array}$} \\
\hline Causes of neonatal jaundice & $\begin{array}{l}\text { Don't know } \\
\text { Food taken during/after pregnancy } \\
\text { Injury during delivery } \\
\text { Inadequate breastfeeding } \\
\text { Inadequate sun exposure } \\
\text { Infection or disease in baby } \\
\text { Effect of sin or evil forces } \\
\text { Blood problems } \\
\text { Born too small or too early before date } \\
\text { Poor hygiene } \\
\text { Jaundice in mother } \\
\text { Occurs without any reason }\end{array}$ & \\
\hline Management of neonatal jaundice & $\begin{array}{l}\text { Nothing needed to be done } \\
\text { Do rituals as advised by faith healers } \\
\text { Avoid certain food } \\
\text { Check blood regularly } \\
\text { Take to hospital and do as doctor says } \\
\text { Keep on special light in hospital } \\
\text { Keep in sunlight } \\
\text { Adequate breastfeeding } \\
\text { Do not know, do as husband or elders in the } \\
\text { family say }\end{array}$ & \\
\hline Outcome of neonatal jaundice & $\begin{array}{l}\text { Do not know } \\
\text { Worrisome } \\
\text { Goes by itself after some days } \\
\text { Takes long time to go away } \\
\text { Dies } \\
\text { Becomes disabled } \\
\text { Requires medicine and blood } \\
\text { Stops feeding and is a danger sign }\end{array}$ & \\
\hline Influences & $\begin{array}{l}\text { Older women in family } \\
\text { Husband } \\
\text { Female community health volunteer } \\
\text { Health worker at local level } \\
\text { Doctor at big hospital } \\
\text { Faith healer } \\
\text { Hearsay or experiences from neighborhood or } \\
\text { relatives }\end{array}$ & \\
\hline
\end{tabular}




\section{CONCEPTUAL FRAMEWORK}



